\title{
Effects of Bleaching Agents, Neutral Fluoride Gels, and Surface Sealants on Enamel Surface Roughness
}

\author{
${ }^{1}$ Burak Gümüştaş, ${ }^{2}$ Özge Gürbüz, ${ }^{3}$ Begüm G Efes
}

\begin{abstract}
Aim: The aim of this in vitro study was to evaluate the surface roughness of enamel after the application of different bleaching agents and to determine the effect of fluoride and bonding agent application on the roughness of bleached enamel.
\end{abstract}

Materials and methods: Forty-two dental slice polished enamel surfaces were randomly assigned to six groups. The surfaces of the slices were treated with $30 \%$ carbamide peroxide (CP) (groups I to III), or $38 \%$ hydrogen peroxide (HP) (groups IV to VI). Groups I and IV were only bleached. Topical fluoride was applied to the bleached surface of groups II and V. Groups III and VI were covered with a bonding agent. The surface roughness was analyzed with a profilometer. Data were subjected to analysis of one-way analysis of variance, Kruskal-Wallis, and Mann-Whitney $U$ tests $(p>0.05)$.

Results: There were no statistically significant differences between the surface roughness of the untreated control specimens and the specimens treated with the bleaching materials, fluoride gel, and dental bonding agent $(p>0.05)$.

Conclusion: Bleaching treatment with $38 \% \mathrm{HP}$ and $30 \% \mathrm{CP}$ does not alter enamel surface roughness.

Clinical significance: The application of topical neutral sodium fluoride agents and dental bonding agents does not have any influence on enamel surface roughness.

Keywords: Enamel, Hydrogen peroxide, Surface properties, Tooth bleaching.

How to cite this article: Gümüştaş B, Gürbüz Ö, Efes BG. Effects of Bleaching Agents, Neutral Fluoride Gels, and Surface Sealants on Enamel Surface Roughness. J Oper Dent Endod 2017;2(2):74-78.

\section{Source of support: Nil}

Conflict of interest: None

\section{INTRODUCTION}

Smile is one of the most important factors in face-to-face social communication between people. Patients' demands

\footnotetext{
${ }^{1,2}$ Assistant Professor, ${ }^{3}$ Professor

${ }^{1,2}$ Department of Restorative Dentistry, Faculty of Dentistry Istanbul Medipol University, Istanbul, Turkey

${ }^{3}$ Department of Operative Dentistry, Faculty of Dentistry, Istanbul University, Istanbul, Turkey

Corresponding Author: Burak Gümüştaş, Assistant Professor Department of Restorative Dentistry, Faculty of Dentistry, Istanbul Medipol University, Istanbul, Turkey, Phone: +902124607777 e-mail: burakgu@gmail.com
}

for esthetic treatments have increased in recent years. Tooth bleaching has proven to be a conservative esthetic solution for tooth discoloration. ${ }^{1,2}$ Hydrogen peroxide is used as an active oxidizing agent during tooth bleaching. It can be used directly or indirectly and is produced by a chemical reaction from $\mathrm{CP}^{3-5}$ Hydrogen peroxide can diffuse through the organic matrix of the tooth structure because of its low molecular weight. ${ }^{6}$

In spite of the good clinical results shown when a high concentration (20-35\%) of HP is used in more than one in-office bleaching session, clinical studies have observed that there was a high prevalence of tooth sensitivity related to this treatment modality (up to $87 \%$ ). ${ }^{7-10}$ This adverse effect is usually considered temporary and mild. However, occasionally, it can produce considerable discomfort to the patient. ${ }^{11}$

Dentists have used several approaches to reduce tooth sensitivity. Reduction in wearing time and frequency of application, temporary interruption of whitening, and the use of an active ingredient, such as potassium nitrate, are commonly used methods by clinicians. ${ }^{12}$ Dentists have also used fluoride as an active agent to reduce sensitivity; ${ }^{13,14}$ however, they usually only apply fluoride after the patient experiences tooth sensitivity. ${ }^{14,15}$

The use of fluoride during or after bleaching has been shown to be beneficial. ${ }^{16-19}$ By forming a calcium fluoride layer on the enamel, which inhibits demineralization or a decrease in microhardness values, it has been proposed that the presence of fluoride may act as a remineralizing agent. In addition, studies have shown that the application of fluoride on softened enamel results in remineralization. ${ }^{16}$ It is not yet known whether a small amount of fluoride, $0.11 \%$, is enough to harden dentin enamel or whether the application of a higher concentration of fluoride, such as 1.23 or $2.23 \%$ (fluoride varnish), is required after a bleaching procedure. ${ }^{20}$

Although tooth bleaching presumably does not create macroscopically visible defects, microscopic alterations could themselves cause undesirable effects. Rough surfaces may predispose the teeth to extrinsic staining, bacteria adhesion, plaque maturation, and periodontal disease. $^{21}$

Topical applications of fluoride and casein phosphopeptide-amorphous calcium phosphate, antibacterial agents incorporated in the adhesive resin could be 
used for reducing or reversing demineralization of the tooth. $^{22}$

Enamel sealants were described by Reynolds, ${ }^{23}$ who included unfilled resins, coupling agents, and silanes in this category. Resin sealants can be useful for enamel protection. $^{24}$

Tooth surface coverage appears to be an immediate, simple, and effective way to protect at-risk enamel. Historically, pit and fissure sealants in newly erupted teeth have been well known to decrease the prevalence of caries. ${ }^{25,26}$ Areas with frequently extensive plaque accumulation adjacent to bonded orthodontic brackets have also been suggested to benefit from extending proper coating materials. ${ }^{27,28}$ Using coating material for hypersensitivity, when there is no loss of dental structure, dentinal adhesives, in the form of bonding agents and varnishes, can be indicated. They produce an immediate effect, but they are easily removed. ${ }^{29}$

Thus, the aim of the current laboratory study was to evaluate the effect of resin coating materials or topical fluoride application on the surface roughness of bleached enamel treated with different concentration of HP. The null hypotheses proposed were that covering enamel by resin material or the application of topical fluoride does not influence the roughness of the enamel and that there were no differences among topical fluoride or surface sealant agents investigated.

\section{MATERIALS AND METHODS}

Freshly extracted, noncarious human maxillary incisors were used in this study. Teeth with visible cracks or hypoplastic defects were excluded. The teeth were cleaned and stored in sterilized saliva at $37^{\circ} \mathrm{C}$ in the incubator (Memmert P 30; Memmert, Schwabach, Germany) until they were used. Whole unstimulated saliva was collected and pooled from one healthy male volunteer aged 22 . The saliva was collected between 9.00 and 10.00 am and the volunteer had not eaten that morning, and had not taken any drugs or medications known to affect saliva production, composition, or flow within the 3 months leading up to the study. Additionally, the volunteer was not taking any antibiotics or antifungal agents. Saliva was centrifuged at $14,000 \mathrm{~g}$ for 15 minutes and then the serous part of the saliva was used immediately. The teeth were sectioned with double-face diamond discs (Discoflex, KG Sorensen, Brazil) to separate the crown and root. Fortytwo $(5 \times 5 \times 2.5 \mathrm{~mm})$ enamel samples were prepared from the buccal surfaces of the teeth using a diamond bur $(\varnothing=5 \mathrm{~mm})$. They were embedded in silicon blocks and finished with sand paper $(1200,2400$, and 4000, Sicpaper, Struers, Denmark) and polishing paste $0.1 \mu \mathrm{m}$ (AP-D Suspension, Struers, Denmark). The samples were randomly divided into six groups $(n=7)$.
The surfaces of the slices were treated with $30 \% \mathrm{CP}$ (White and Brite, 3M ESPE, St. Paul, MN) (groups I to III) or $38 \%$ HP (Opalescence Boost, Ultradent, South Lake, UT) (groups IV to VI) for 20 minutes. This was repeated twice according to the manufacturer's instructions. The bleaching gel was applied to the complete surface of specimens in a $1 \mathrm{~mm}$ thick layer. Subsequently, the bleaching products were meticulously removed from the surfaces with a foam pellet (Pele Tim, Voco, Cuxhaven, Germany) and were washed with water for 10 seconds and dried with compressed air for 5 seconds. Excessive water was carefully removed with a cellulose cloth (Hake-Kimberley, Mainz, Germany).

The bleaching gel material was sectioned with a section device and samples before the application of fresh material. All of the samples were stored in sterilized saliva at $37^{\circ} \mathrm{C}$ over the course of the experiment. Groups I and IV were only treated with bleaching materials. The bleaching gel material was sectioned with section device and samples before the application of fresh material. All of the samples were stored in sterilized saliva at $37^{\circ} \mathrm{C}$ over the course of the experiment. Groups I and IV were only treated with bleaching materials. Neutral fluoride (Denti-Care Denti-Pro Gel 2\% Neutral Sodium Fluoride, Medicom, Canada) was applied for 4 minutes to the bleached surface in groups II and V. The bleached surfaces were covered with a bonding agent in groups III and VI (Kuraray Protect Bond, Kuraray Dental, Kurashiki, Japan) (Table 1). The surface roughness ( $\mathrm{Ra}$ ) of the specimens was analyzed with a profilometer (Surtronic 25, Taylor Hobson, UK) before any application which was stored in sterilized saliva for 24 hours (control specimens values) and 24 hours after treatment. The Ra value is the arithmetic mean line calculated by the analyzer. Three traces were recorded for each specimen on three different locations. The roughness value was recorded as the average of these three readings. A calibration block was used periodically to check the performance of the profilometer. The equipment consistently provided an accurate recording of the calibration block $(3.10 \pm 0.10 \mu \mathrm{m})$ when performed at three different areas for each sample. The difference of Ra values of all groups were calculated before and after fluor or bonding agent treatment or store saliva only, then $\Delta \mathrm{Ra}$ was calculated. Statistical analyses were performed using one-way analysis of variance, Kruskal-Wallis, and Mann-Whitney $U$ tests. Statistical significance was accepted at $\mathrm{p}<0.05$.

\section{RESULTS}

The means and standard deviations of the surface roughness of the specimens and $\Delta$ Ra values are shown in Table 2. There were no statistically significant differences between 
Table 1: Material used in the study

\begin{tabular}{|c|c|c|}
\hline Material & Manufacturer & Contents \\
\hline \multicolumn{3}{|l|}{ Bleaching material } \\
\hline White and Brite & 3M ESPE, St. Paul, MN & $30 \% \mathrm{CP}$ \\
\hline Opalescence boost & Ultradent, South Lake, UT & $38 \% \mathrm{HP}$ \\
\hline \multicolumn{3}{|l|}{ Fluor agent } \\
\hline Denti-Pro & Denti-Care, Medicom, Canada & $2 \%$ Neutral sodium fluoride \\
\hline \multicolumn{3}{|l|}{ Surface sealant agent } \\
\hline Protect bond & Kuraray, Kuraray Dental, Kurashiki, Japan & $\begin{array}{l}\text { Nanofiller type: Silanated colloidal silica; Surface-treated } \\
\text { sodium fluoride ( } \mathrm{NaF}<1 \%)\end{array}$ \\
\hline
\end{tabular}

Table 2: Mean and standard deviation of the surface roughness (Ra) of the specimens

\begin{tabular}{lllll}
\hline Groups & Application & $R a$ (before) & $R a$ (after) & $\Delta R a$ \\
\hline I & $30 \%$ CP & $0.59(0.15)$ & $1.01(0.59)$ & $0.42^{\mathrm{b}}$ \\
II & $30 \% \mathrm{CP}+\mathrm{F}$ & $0.52(0.22)$ & $0.83(0.36)$ & $0.31^{\mathrm{ab}}$ \\
III & $30 \% \mathrm{CP}+\mathrm{SS}$ & $0.56(0.36)$ & $1.04(0.35)$ & $0.48^{\mathrm{b}}$ \\
IV & $38 \% \mathrm{HP}$ & $0.71(0.26)$ & $0.90(0.36)$ & $0.19^{\mathrm{a}}$ \\
V & $38 \% \mathrm{HP}+\mathrm{F}$ & $0.77(0.43)$ & $0.97(0.41)$ & $0.20^{\mathrm{a}}$ \\
VI & $38 \% \mathrm{HP}+\mathrm{SS}$ & $0.95(0.43)$ & $1.22(0.63)$ & $0.27^{\mathrm{ab}}$ \\
\hline
\end{tabular}

the surface roughness of the untreated control specimens and the specimens treated with the bleaching materials, fluoride gel, and a dental bonding agent ( $p>0.05)$.

Significant differences were not found between any of the procedures in any of the groups $(p>0.05)$. None of the groups showed a statistical difference in Ra after treatment with bonding and fluoride agents. With regard to the groups, there were no statistically significant differences between the Ra values. Columns A and B in Graph 1 indicate surface roughness before and after treatment respectively.

\section{DISCUSSION}

The findings of the present experiment confirm the null hypothesis which was that the enamel surface roughness is not affected by $30 \% \mathrm{CP}, 38 \% \mathrm{HP}$ application, regardless of treatment with neutral topical fluoride or surface sealant. The surface roughness of the enamel did not increase after bleaching with $30 \% \mathrm{CP}$ or $38 \% \mathrm{HP}$, and significant differences were not found in any of the roughness parameters when the initial and after-bleaching values were compared.

$\mathrm{Ra}$ is the most frequently reported parameter for measuring surface roughness in dental studies. Additional roughness parameters allow for further assessment of surface quality. ${ }^{16}$

Surface roughness parameters were negatively correlated with the parameters of surface microhardness. ${ }^{30,31}$ The results from the surface profilometer also demonstrated that Ra values were not significantly higher compared to the control after application of $38 \% \mathrm{HP}$ or $30 \% \mathrm{CP}$.

In vitro models can be used to gain important information on the safety of products in terms of their effects on

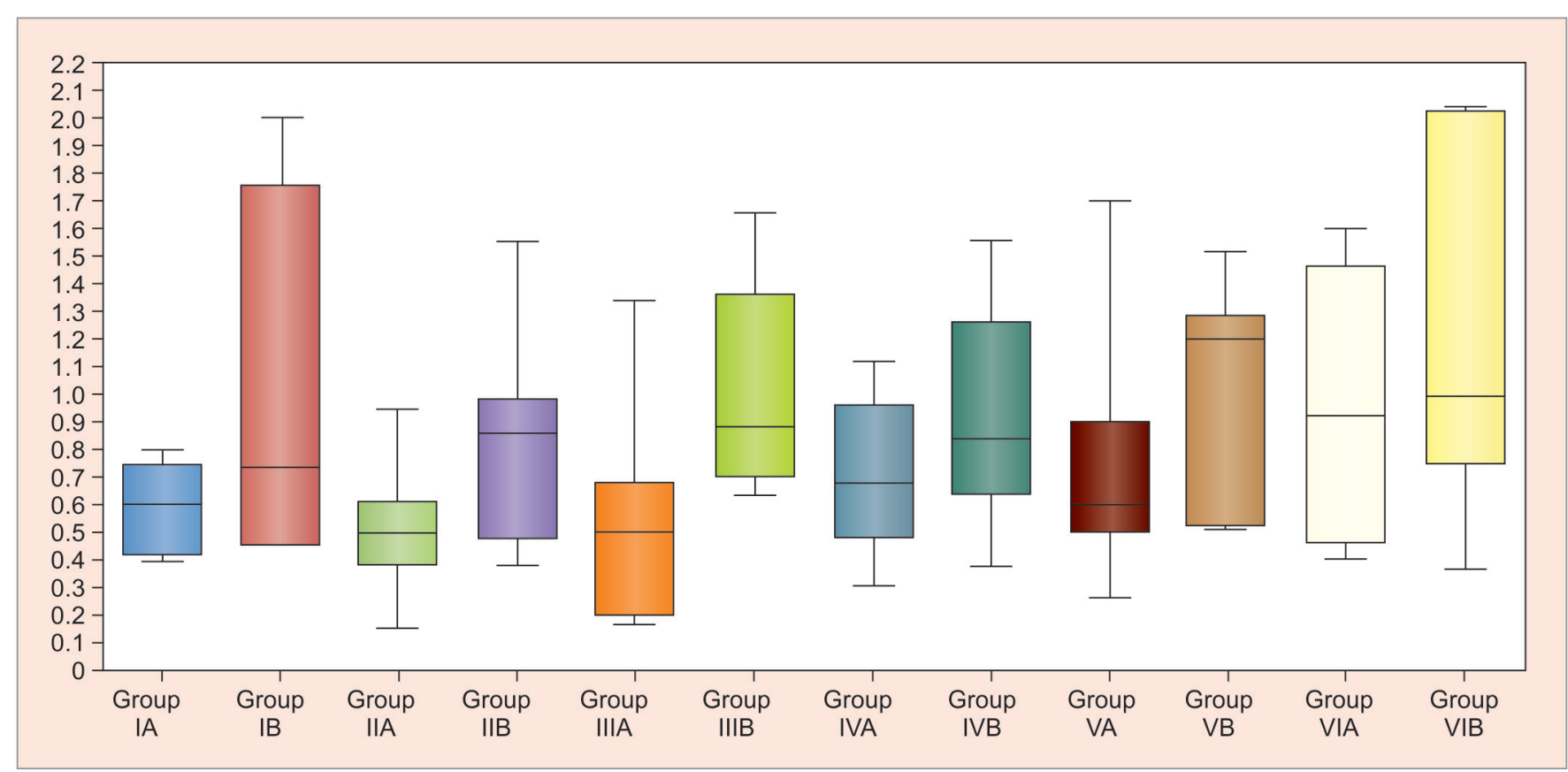

Graph 1: Statistical results of tooth surface roughness. A columns indicate surface roughness before treatment, B columns indicate after treatment 
hard tissues and to provide a mechanistic understanding of the bleaching process. This laboratory study was undertaken to evaluate the impact of $30 \% \mathrm{CP}$ and $38 \%$ $\mathrm{HP}$ bleaching gels, a bonding agent, and neutral fluoride on surface roughness. Thus, $\mathrm{CP}$ and HP are the most common agents used for tooth whitening. ${ }^{32}$ When HP comes in contact with the outer enamel surface, it breaks down into water and oxygen, which diffuse through the organic content of the enamel. ACP agent was introduced as an alternative to a traditional $\mathrm{HP}$ one, as its use has become widespread. This agent is very unstable and it immediately breaks down into its constituent parts on contact with tissue and saliva, dissociating primarily into HP and urea and further into oxygen, water, and carbon dioxide. ${ }^{33}$ This causes oxidation of organic pigments that are mainly located within dentin; this results in a reduction or elimination of the discoloration. The approximate equivalent of $3.3 \% \mathrm{HP}$ is $10 \% \mathrm{CP}$. In accordance with Habelitz et $\mathrm{al}^{34}{ }^{34}$ a cyclic model including periods of bleaching and remineralization with sterilized saliva were used in this study to simulate physiological conditions during bleaching procedures. It was assumed that a bleaching period of 8 hours reflects the clinical situation. The amount of $\mathrm{CP}$ that was chosen was sufficient to completely cover the surface of the enamel and dentin.

Fluoride remineralizes dental erosion lesions by increasing resistance to acid attacks through the formation of a calcium fluoride layer, which inhibits demineralization. The effect of postbleaching fluoridation has been confirmed in previous investigations. Attin et al evaluated the remineralizing capacity of various fluoride treatments after bleaching treatment. Both fluoride varnish and solution prevented loss of hardness after bleaching. ${ }^{35}$ According to de Oliveira et $\mathrm{al}^{30}$ using a desensitizing fluoride dentifrice along with a bleaching treatment maintained the enamel roughness at baseline values. In contrast to these studies, the present study evaluated the effect of fluoride on bleached enamel through approaches that included postbleaching fluoridation and fluoridated bleaching agents. Despite the widespread clinical use of fluoridated bleaching agents, their efficacy had not been thoroughly evaluated.

Previous studies that investigated the demineralization effects of in-office bleaching agents on tooth structures have provided controversial results. Although Sulieman et al ${ }^{31}$ reported no significant changes in hardness values for enamel and dentin after bleaching with $35 \% \mathrm{HP}$, Attin et $\mathrm{al}^{32,33}$ and Lewinstein et $\mathrm{al}^{18}$ reported a significant reduction in the Knoop hardness of enamel after application of $35 \% \mathrm{CP}$.

Buren et $\mathrm{al}^{36}$ utilized the depth of enamel demineralization and the surface appearance to evaluate the effectiveness of filled resin sealant in inhibiting enamel demineralization. A fluoride varnish and an unfilled resin sealant that have demonstrated success in white spot prevention were used for comparison. Enamel surfaces were also examined visually for signs of decalcification. The filled resin sealant shows promise as an effective method of preventing enamel demineralization without relying on patient compliance. ${ }^{37}$ The findings of this study demonstrate that the dentin adhesives did not alter the surface with respect to surface roughness. However, bonding agents could play an important role in establishing a protective sealing strategy and a desensitizing effect after the bleaching procedure.

\section{CONCLUSION}

The results of surface roughness evaluations indicate that enamel is not altered in a bleaching agent-dependent fashion. In this in vitro study, the influences of vital bleaching on the enamel surface were observed using extracted human teeth. The results showed that vital bleaching treatment, the covering of teeth with a bonding agent, and the application of neutral fluoride do not induce changes in the roughness of the enamel surface.

\section{REFERENCES}

1. Burrows S. A review of the efficacy of tooth bleaching. Dent Update 2009 Nov;36(9):537-538, 541-544, 547-548.

2. Féliz-Matos L, Hernández LM, Abreu N. Dental bleaching techniques; Hydrogen-carbamide peroxides and light sources for activation, an update. Mini review article. Open Dent J 2015 Jan;8:264-268.

3. Tredwin CJ, Naik S, Lewis NJ, Scully C. Hydrogen peroxide tooth-whitening (bleaching) products: review of adverse effects and safety issues. Br Dent J 2006 Apr;200(7):371-376.

4. Dahl JE, Pallesen U. Tooth bleaching - a critical review of the biological aspects. Crit Rev Oral Biol Med 2003;14(4): 292-304.

5. Markovic L, Jordan RA, Lakota N, Gaengler P. Micromorphology of enamel surface after vital tooth bleaching. J Endod 2007 May;33(5):607-610.

6. Hannigh C, Weinhold HC, Becker K, Attin T. Diffusion of peroxides through dentine in vitro with and without prior use of a desensitizing varnish. Clin Oral Investig 2011 Dec;15(6):863-868.

7. Marson FC, Sensi LG, Vieira LC, Araújo E. Clinical evaluation of in-office dental bleaching treatments with and without the use of light-activation sources. Oper Dent 2008 JanFeb;33(1):15-22.

8. Kossatz S, Dalanhol AP, Cunha T, Loguercio A, Reis A. Effect of light activation on tooth sensitivity after in-office bleaching. Oper Dent 2011 May-Jun;36(3):251-257.

9. Reis A, Dalanhol AP, Cunha TS, Kossatz S, Loguercio AD. Assessment of tooth sensitivity using a desensitizer before light-activated bleaching. Oper Dent 2011 Jan-Feb;36(1):12-17.

10. Almeida LC, Riehl H, Santos PH, Sundfeld ML, Briso AL. Clinical evaluation of the effectiveness of different bleaching therapies in vital teeth. Int J Periodontics Restorative Dent 2012 Jun;32(3):303-309. 
11. Leonard RH Jr, Smith LR, Garland GE, Tiwana KK, Zaidel LA, Pugh G Jr, Lin NC. Evaluation of side effects and patients' perceptions during tooth bleaching. J Esthet Restor Dent 2007;19(6):355-364.

12. Haywood VB. Treating sensitivity during tooth whitening. Compend Contin Educ Dent 2005 Sep;26(9 Suppl 3):11-20.

13. Barghi N. Making a clinical decision for vital tooth bleaching: at-home or in-office? Compend Contin Educ Dent 1998 Aug;19(8):831-838.

14. Haywood VB, Caughman WF, Frazier KB, Myers ML. Tray delivery of potassium nitrate-fluoride to reduce bleaching sensitivity. Quintessence Int 2001 Feb;32(2):105-109.

15. Armênio RV, Fitarelli F, Armênio MF, Demarco FF, Reis A, Loguercio AD. The effect of fluoride gel use on bleaching sensitivity: a double-blind randomized controlled clinical trial. J Am Dent Assoc 2008 May;139(5):592-597.

16. Attin T, Kielbassa AM, Schwanenberg M, Hellwig E. Effect of fluoride treatment on remineralization of bleached enamel. J Oral Rehabil 1997 Apr;24(4):282-286.

17. Attin T, Kocabiyik M, Buchalla W, Hannig C, Becker K. Susceptibility of enamel surfaces to demineralization after application of fluoridated carbamide peroxide gels. Caries Res 2003 Mar-Apr;37(2):93-99.

18. Lewinstein I, Fuhrer N, Churaru N, Cardash H. Effect of different peroxide bleaching regimens and subsequent fluoridation on the hardness of human enamel and dentin. J Prosthet Dent 2004 Oct;92(4):337-342.

19. Bizhang M, Seemann R, Duve G, Römhild G, Altenburger JM, Jahn KR, Zimmer S. Demineralization effects of 2 bleaching procedures on enamel surfaces with and without posttreatment fluoride application. Oper Dent 2006 Nov-Dec;31(6): 705-709.

20. da Costa JB, Mazur RF. Effects of new formulas of bleaching gel and fluoride application on enamel microhardness: an in vitro study. Oper Dent 2007 Nov-Dec;32(6):589-594.

21. Moraes RR, Marimon JL, Schneider LF, Correr Sobrinho L, Camacho GB, Bueno M. Carbamide peroxide bleaching agents: effects on surface roughness of enamel, composite and porcelain. Clin Oral Investig 2006 Mar;10(1):23-28.

22. Montasser MA, Taha M. Effect of enamel protective agents on shear bond strength of orthodontic brackets. Prog Orthod 2014 Jul;15:34.

23. Reynolds IR. A review of direct orthodontic bonding. Br J Orthod 1976;2(3):171-178.

24. Banks PA, Richmond S. Enamel sealants: a clinical evaluation of their value during fixed appliance therapy. Eur J Orthod 1994 Feb;16(1):19-25.
25. Wegehaupt FJ, Tauböck TT, Attin T. Durability of the antierosive effect of surfaces sealants under erosive abrasive conditions. Acta Odontol Scand 2013 Sep;71(5):1188-1194.

26. Kantovitz KR, Pascon FM, Correr GM, Borges AF, Uchôa MN, Puppin-Rontani RM. Inhibition of mineral loss at the enamel/ sealant interface of fissures sealed with fluoride- and nonfluoride containing dental materials in vitro. Acta Odontol Scand 2006 Nov;64(6):376-383.

27. Bechtold TE, Sobiegalla A, Markovic M, Berneburg M, Göz GR. In vivo effectiveness of enamel sealants around orthodontic brackets. J Orofac Orthop 2013 Nov;74(6):447-457.

28. Alsayed EZ, Hariri I, Nakashima S, Shimada Y, Bakhsh TA, Tagami J, Sadr A. Effects of coating materials on nanoindentation hardness of enamel and adjacent areas. Dent Mater 2016 Jun;32(6):807-816.

29. Duran I, Sengun A. The long-term effectiveness of five current desensitizing products on cervical dentine sensitivity. J Oral Rehabil 2004 Apr;31(4):351-356.

30. de Oliveira R, Basting RT, Rodrigues JA, Rodrigues AL Jr, Serra MC. Effects of a carbamide peroxide agent and desensitizing dentifrices on enamel microhardness. Am J Dent 2003 Feb;16(1):42-46.

31. Sulieman M, Addy M, Macdonald E, Rees JS. A safety study in vitro for the effects of an in-office bleaching system on the integrity of enamel and dentine. J Dent 2004 Sep;32(7): 581-590.

32. Attin T, Müller T, Patyk A, Lennon AM. Influence of different bleaching systems on fracture toughness and hardness of enamel. Oper Dent 2004 Mar-Apr;29(2):188-195.

33. Attin T, Vollmer D, Wiegand A, Attin R, Betke H. Subsurface microhardness of enamel and dentin after different external bleaching procedures. Am J Dent 2005 Feb;18(1):8-12.

34. Habelitz S, Balooch M, Marshall GW, Breunig TM, Marshall SJ. AFM-based nanomechanical properties and storage of dentin and enamel. Mater Res Soc Symp Proc. 2001;676:Y.3.27.1-Y. 3.27.5.

35. Faraoni-Romano JJ, Da Silveira AG, Turssi CP, Serra MC. Bleaching agents with varying concentrations of carbamide and/or hydrogen peroxides: effect on dental microhardness and roughness. J Esthet Restor Dent 2008;20(6):395-404.

36. Buren JL, Staley RN, Wefel J, Qian F. Inhibition of enamel demineralization by an enamel sealant, Pro Seal: an in-vitro study. Am J Orthod Dentofacial Orthop 2008 Apr;133(4 Suppl):S88-S94.

37. Davidson CL, Bekke-Hoekstra IS. The resistance of superficially sealed enamel to wear and carious attack in vitro. J Oral Rehabil 1980 Jul;7(4):299-305. 